\title{
EFFECTIVENESS OF GLYCERYL TRINITRATE TRANSDERMAL PATCH IN PRETERM LABOUR: A PROSPECTIVE STUDY
}

\author{
Chandana $\mathrm{C}^{1}$, Kasturi V. Donimath ${ }^{2}$
}

\section{HOW TO CITE THIS ARTICLE:}

Chandana C, Kasturi V. Donimath. "Effectiveness of Glyceryl Trinitrate Transdermal Patch in Preterm Labour: A Prospective Study". Journal of Evolution of Medical and Dental Sciences 2014; Vol. 3, Issue 11, March 17; Page: 2699-2705, DOI: $10.14260 /$ jemds/2014/2195

ABSTRACT: OBJECTIVE: To assess the effectiveness and safety of Glyceryl trinitrate transdermal patch, a nitric oxide donor in the treatment of preterm labor and fetomaternal outcome. METHODS: A prospective study was conducted in the department of obstetrics and gynecology, Karnataka institute of medical sciences, Hubli, from June 2008 to May 2009. Sixty pregnant women at 28-34 weeks of gestation were recruited after they met the inclusion criteria. Fifty out of sixty pregnant women completed treatment and ten patients did not come for follow-up or refused to continue. Patients diagnosed with pre-term labor were given glyceryl trinitrate (GTN) $10 \mathrm{mg} / 24$ hours transdermal patch which was applied on the anterior abdominal wall. The second patch of same dose was given after 24 hours. Arrest of labor, prolongation of pregnancy in days or weeks along with side effects were monitored. Patients were followed till delivery to know the feto-maternal outcome. RESULTS: Prolongation of gestational age by more than 48 hours was seen in 45 patients (90\%) out of 50. Five patients delivered within 48hours which was considered as treatment failure. Mean prolongation of gestation was $23.8 \pm 15.5$ days. Maximum prolongation of gestation was 40 days. The average birth weight is $2.1 \mathrm{kgs}$. In the present study headache was the most common side effect observed in $14(28 \%)$ patients, tachycardia in $6(12 \%)$ patients and hypotension in $3(6 \%)$ patients. CONCLUSION: Glyceryl trinitrate transdermal patch appear to be a safe, well tolerated, and noninvasive method of suppressing uterine contractions in preterm labor. Headache was the most common maternal side effect noticed. However, before its widespread use can be recommended, large double blind multicenter trials are needed to assess optimal dosage, dosage regimes, overall efficacy and fetal safety.

KEYWORDS: Transdermal glyceryl trinitrate patch, tocolysis, preterm labor.

INTRODUCTION: Preterm labor is defined as the onset of uterine contractions of sufficient strength and frequency to effect the progressive dilatation and effacement of cervix between 20-37 weeks of gestation. Birth before 37weeks gestational age complicates $5-10 \%$ of all pregnancies and $1-2 \%$ of pregnancies before 32 weeks. ${ }^{1}$ It is a major public health problem in terms of loss of life, long term disability (cerebral palsy, blindness, deafness, chronic lung disease) and health care costs both in the developing and developed countries. In addition, developing countries are unable to cope with the health care costs associated with managing neonates that are born preterm, resulting in higher and often unacceptable neonatal morbidity and mortality. Tocolytics are pharmacological agents that relax the uterine myometrium and inhibit uterine contractions leading to abolition of preterm labor.

Many tocolytic drugs have been developed and used and several experimental drugs are being evaluated. The tocolytic drugs like Beta sympathomimetics, Calcium channel blockers, Magnesium sulphate, Oxytocin antagonists and Prostaglandin synthetase inhibitors are used. These 
tocolytic drugs are associated with serious maternal and fetal side effects and require strict monitoring of both mother and fetus due to their adverse effects. ${ }^{2}$

Nitric oxide donors are not new they have been used as vascular smooth muscle relaxants for a long time in cardiac conditions. Nitroglycerine was first synthesized about 150 years ago. Nitroglycerine is a potent smooth muscle relaxant that has been used to relax the uterus during the removal of retained placenta, correction of uterine inversion, facilitation of fetal extraction during caesarean section and intra partum version of second twin. ${ }^{3}$ Nitroglycerine (nitric oxide donors) may be an effective choice as a tocolytic agent due to its safety profile with infrequent maternal and fetal side effects. ${ }^{4}$

MATERIAL AND METHODS: A prospective study was conducted in the department of obstetrics and gynecology, Karnataka institute of medical sciences, Hubli, from June 2008 to May 2009. Initially sixty pregnant women at 28-34 weeks of gestation were recruited after they met the inclusion criteria. Out of sixty selected patients fifty patients completed treatment and ten patients did not come for followup or refused to continue.

INCLUSION CRITERIA: Women with singleton pregnancy with uterine contractions 2 per 10 min or 4 per 20 min between 28 to 34 weeks of gestation with,

- Cervical dilatation of $0-3 \mathrm{~cm}$

- Cervical effacement up to $80 \%$

- Intact membranes

\section{EXCLUSION CRITERIA:}

- Hypotension (Systolic BP $\leq 80 \mathrm{~mm}$ of $\mathrm{Hg}$ ) and maternal tachycardia pulse rate $>100 / \mathrm{min}$

- Fetal congenital malformation and Intra uterine fetal demise

- Antepartum hemorrhage

- Rupture of membranes

- Fetal distress

- Uterine tenderness with or without offensive vaginal discharge

- Pregnancy associated with medical disorders, pregnancy induced hypertension

- Multiple gestation

After taking written informed consent, Patients diagnosed with pre-term labor were given nitroglycerine $10 \mathrm{mg} / 24$ hours transdermal patch which was applied on the anterior abdominal wall. The second patch of same dose was given after 24 hours. And the patient vital signs and fetal heart rate was closely monitored. The patients are carefully observed for the presence of side effects such as headache, hypotension, flushed face, dizziness, nausea, vomiting, and for abnormalities of fetal heart rate pattern. If the side effects are intense, the patch is removed. If contractions did not decrease in strength or in frequency after two hours, a second patch containing $10 \mathrm{mg}$ is applied. The maximum dose of nitroglycerine in any 24 hour period is $20 \mathrm{mg}$.

If contractions subside, the treatment is continued until uterine contractions are absent for 24 hours and then the woman is observed for another 48 hours for uterine contractions. The patient is discharged without any maintenance tocolytic drug and assessed antenatally every week till delivery. A repeat episode of preterm labor is treated in the same manner. All patients are given 
injection betamethasone [12mg] intramuscularly at the time of admission and again after 24 hours. Blood samples for complete blood picture, blood sugar, urine for detailed report, and high vaginal swab were taken at admission to rule out any infection. Ultrasound was done for fetal well-being and to exclude uterine anomalies.

The outcome of treatment was the prolongation of pregnancy or delivery in hours or days after the start of tocolytic therapy and was deemed successful if delivery was deferred for at least 48 hours. At delivery APGAR score and the weight of the newborn were recorded on the predesigned proforma. Data analysis was done with the help of SPSS software (version 10.0). Frequency and percentage were computed for categorical variables like doses of nitroglycerine patch, uterine contractions, maternal side effects, neonatal APGAR score/weight and gestational age prolongation period. Mean and standard deviation were computed for quantitative variables and analyzed by applying Pearson test .The results are statistically analyzed as prolongation of gestation from initiation of treatment to delivery or to 37 weeks of gestation.

RESULTS: The study group included 60 patients with preterm labor. 10 patients did not come for follow-up, hence excluded from the study. The majority of the patients belonged to 21-25 yr. age group (68\%), followed by more number of patients in 18-20 years age group (20\%) as shown in the table 1 . The majority of the patients were multigravida (62\%) with previous history of preterm labor present in $20 \%$ patients as shown in the table 2 . Gestational age wise distribution among patients is given in table 3 and majority of the patients belonged to $30-32$ weeks of gestation (60\%). Success rate that is prolongation of gestational age by more than 48 hours was $90 \%$.

Five patients delivered within 48 hours which was considered as treatment failure. Mean prolongation of gestation was $23.8 \pm 15.8$ days. Maximum prolongation of gestation was 40 days in one patient. In our study, pregnancy was prolonged beyond 37 weeks in 11 patients. The postponement of delivery by less than one week in 9 patients, one to three weeks in 12 patients, four to six weeks in 14 patients, seven to nine weeks in 8 patients and more than ten weeks in 2 patients as shown in table 4 . In the present study 12 babies had birth weight more than $2.5 \mathrm{kgs}, 25$ babies had birth weight between $1.5-2.5$ kgs, 13 babies had birth weight less than 1.5 kgs. The average birth weight is $2.1 \mathrm{kgs}$. There are five neonatal deaths, because of extreme prematurity.

In the present study headache was the most common side effect observed in $14(28 \%)$ of patients, tachycardia in $6(12 \%)$ of patients and hypotension in $3(6 \%)$ of patients as shown in table 5. No patient had skin rash or itching at the site of application. Glyceryl trinitrate Transdermal patches are well tolerated and none of the side effect warrants the withdrawal of treatment.

\begin{tabular}{|c|c|c|}
\hline AGE & Number of Patients & Percentage (\%) \\
\hline 18- 20years & 15 & 30 \\
\hline 21-25years & 19 & 38 \\
\hline 26-30years & 12 & 24 \\
\hline 31-35years & 4 & 8 \\
\hline Total & $\mathbf{5 0}$ & $\mathbf{1 0 0}$ \\
\hline \hline \multicolumn{2}{|c|}{ Table 1: Patient distribution according to age } \\
\hline
\end{tabular}




\begin{tabular}{|c|c|c|}
\hline & No. of patients & Percentage (\%) \\
\hline Primigravida & 19 & 38 \\
\hline Multigravida & 31 & 62 \\
\hline
\end{tabular}

Table 2: Patient distribution according to gravida

\begin{tabular}{|c|c|c|}
\hline Gestational age (week) & No. of patients & Percentage (\%) \\
\hline $28-29$ & 13 & 26 \\
\hline $30-31$ & 10 & 20 \\
\hline $32-33$ & 17 & 34 \\
\hline 34 & 10 & 20 \\
\hline TOTAL & $\mathbf{5 0}$ & $\mathbf{1 0 0}$ \\
\hline
\end{tabular}

Table 3: Pregnant women distribution of gestational age at treatment

\begin{tabular}{|c|c|}
\hline Duration & No. of patients \\
\hline$<48$ hours & 5 \\
\hline $3-7$ days & 9 \\
\hline 1-3 weeks & 12 \\
\hline $4-6$ weeks & 14 \\
\hline 7-9 weeks & 8 \\
\hline 10 weeks & 2 \\
\hline
\end{tabular}

Table 4: Prolongation of gestation in

Pregnant women after treatment

\begin{tabular}{|l|c|c|}
\hline \multicolumn{1}{|c|}{ SIDE EFFECT } & NO. OF PATIENTS & PERCENTAGE (\%) \\
\hline HEADACHE & 14 & 28 \\
\hline TACHYCARDIA & 6 & 12 \\
\hline HYPOTENSION & 3 & 6 \\
\hline SKIN RASH/ITCHING & 0 & 0 \\
\hline CHEST PAIN, PALPITATION & 0 & 0 \\
\hline \multicolumn{2}{|c|}{ Table 5: GTN transdermal patch induced maternal side effects } \\
\hline
\end{tabular}

DISCUSSION: Preterm labor and delivery are very challenging obstetric complications encountered by obstetricians, as are preterm neonates for pediatricians. The incidence of preterm labor is rising world over because of increased frequency of multiple births due to assisted reproductive techniques, more working mothers, increasing psychological stress and medically induced prematurity. ${ }^{5}$ Tocolytics are pharmacological agents that relax the uterine myometrium and inhibit uterine contractions leading to abolition of preterm labor.

Delaying the delivery has two-fold benefits: one is to get enough time to complete the course of antepartum glucocorticosteroids in order to reduce the incidence and severity of respiratory distress syndrome while arranging for in utero transfer to a center with services for dealing with 
even extreme prematurity; and the second benefit is to reduce the perinatal mortality and morbidity associated with severe prematurity.

Nitric oxide is an important modulator of contractile function in a variety of smooth muscle types. In pregnancy there is an increasing evidence for the up regulation of the enzyme nitric oxide synthetase possibly through the action of estrogen. ${ }^{6}$ Nitric oxide also been implicated in peripheral vasodilatation in pregnancy and in the control of blood flow in the fetoplacental circulation. ${ }^{7}$ More recently it has been hypothesized that nitric oxide plays a role in the maintenance of uterine quiescence during pregnancy as nitric oxide donors inhibit placental CRH secretion. ${ }^{8}$ Taken together these observations suggest that a deficiency of nitric oxide production could contribute to preterm labor and have fuelled the current interest in the use of nitric oxide donors as tocolytic agents.

During the current study Success rate that is prolongation of gestational age by more than 48 hours, was seen in 45 patients (90\%). This result is comparable with majority of the below mentioned studies as shown in Table 6.

\begin{tabular}{|l|c|}
\hline \multicolumn{1}{|c|}{ Study } & Success rate (\%) \\
\hline Lees et al $^{9}$ & 92 \\
\hline${\text { Usha Krishna et } \mathrm{al}^{10}}{ }^{10}$ & 100 \\
\hline Krishna UR et al $^{11}$ & 92 \\
\hline Arun Kumar et al $^{12}$ & 95 \\
\hline Present study & 90 \\
\hline Table 6: Showing success rate in different studies \\
\hline
\end{tabular}

Five patients delivered within 48 hours which was considered as treatment failure. Mean prolongation of gestation was $23.8 \pm 15.5$ days. Maximum prolongation of gestation was 40 days and average birth weight was 2.1 kgs. The low average birth weight noted in the present study may be because, the majority of the patients belonged to low socio economic status and their low nutritional status. Krishna UR et al ${ }^{11}$ in their study found mean birth weight was $2.57 \mathrm{~kg}$ and Graeme N Smith et al ${ }^{4}$ found in their study mean birth weight was $2.543 \mathrm{~kg}$.

Perinatal outcome is directly related to pregnancy prolongation, which is comparable to many studies utilizing GTN in premature labor in their comparative trials using either placebo or other drugs.

The first observational study of effect of glyceryl trinitrate patches on uterine contractions was done by Chirstoph Lees and Stuart Campbell who studied 13 women admitted consecutively in preterm labor. All twenty episodes of preterm labor between 23- 33 weeks of gestation responded. The mean prolongation of pregnancy was 34 days. They considered GTN patches as safe and well tolerated.9' In a randomized controlled study tocolysis with nitric oxide donor, it was found that transdermal glyceryl trinitrate was effective in delaying the pregnancy beyond 48 hours and prolonging gestation to 37 weeks and out of 153 women 74 who received a nitroglycerine patch had reduced neonatal complications compared to the 79 who had received a placebo. ${ }^{13}$

All kinds of tocolytics are associated with one or the other side effect. In the present study headache was the most common side effect observed in 14 (28\%) of patients, tachycardia in $6(12 \%)$ of patients, hypotension in $3(6 \%)$ of patients. These were treated with stat dose of simple analgesic (tablet paracetamol), oral fluids and intravenous fluids respectively. Arun Kumar et al, in their study 
observed that headache in $12 \%$ of patients. ${ }^{12}$ Krishna UR et al, in his study found that headache $(12.5 \%)$ was the most common maternal side effect.11 Thus the results in the present study are in concurrence with the above mentioned studies. Headache is the commonest side effect seen with glyceryl trinitrate patch, which is due to meningeal vasodilatation and can be readily treated with paracetamol.

The present study suggests that transdermal nitroglycerine is promising as a safe, effective means of tocolytic. It is well tolerated by the patients with few maternal side effects. It is non-invasive and its ease of administration has made patients to accept it. However before its widespread use can be recommended, large multicenter trials are needed to assess optimal dosage, dosage regimes, overall efficacy and fetal safety.

CONCLUSIONS: Glyceryl trinitrate transdermal patch appear to be a safe, well tolerated, and noninvasive method of suppressing uterine contractions in preterm labor. Headache was the most common maternal side effect noticed. Nitroglycerine (nitric oxide donors) may be an effective choice as a tocolytic agent due to its safety profile with infrequent maternal and fetal side effects. However, before its widespread use can be recommended, large double blind multicenter trials are needed to assess optimal dosage, dosage regimes, overall efficacy and fetal safety.

\section{REFERENCES:}

1. Junejo N, Mumtaz F, Unar BA. Comparison of salbutamol and nifedipine as a tocolytic agent in the treatment of preterm labor. J Liaquat Uni Med Health Sci 2008; 7: 115-9.

2. De Renzo GC, Roura LC. Guideline for the management of preterm labour: international guideline. Berlin. New York: Walter de Gruter 2006; 34: 359-66.

3. Jones GD, Poston L. The role of endogenous nitric oxide synthesis in contractility of term or preterm human myometrium. Br J Obstet Gynaecol. 1997 Feb; 104 (2):241-5.

4. Smith GN, Walker MC, Ohlsson A, O'Brien K, Windrim R. Canadian Preterm Labour Nitroglycerin Trial Group. Randomized double-blind placebo-controlled trial of transdermal nitroglycerin for preterm labor. Am J Obstet Gynecol. 2007 Jan; 196(1):37.

5. Singh U, Singh N, Seth S. A prospective analysis of etiology and outcome of preterm labour. J Obstet Gynaecol India vol.57, No1: January/February 2007; 48-52.

6. Homson A, Norman J. Biology of preterm labour. In: Norman JE, Greer IA editors. Preterm labour managing risk in clinical Practice. Cambridge University Press, 2006; 2: 26-76.

7. Mirteimoori M, Sakhawar N, Teimoori B. Glyceryl trinitrate verses Magnesium sulphate in the suppression of Preterm labour. SMJ 2009; 10: 2.

8. Diejomaoh MF, Omu AE, Taher S, Al-Busiri N, Fatinikun T, Fernandes S, Al-Othman S. Nitric oxide metabolites in preterm and induced labor. Gynecol Obstet Invest. 2003; 56(4):197-202.

9. Lees C, Campbell S, Jauniaux E, Brown R, Ramsay B, Gibb D, Moncada S, Martin JF. Arrest of preterm labour and prolongation of gestation with glyceryl trinitrate, a nitric oxide donor. Lancet. 1994 May 28; 343(8909):1325-6.

10. Krishna U, Damle DS. Nitroglycerine skin patch application for tocolysis in premature onset of labour. J Obstet Gynaec Today 1(4); pg 305-307: 1996.

11. Krishna UR. Study of nitroglycerine application for tocolysis in preterm labour. Preterm labour. New Delhi; Jaypee Brothers, 1998 pg 157-160. 


\section{ORIGINAL ARTICLE}

12. Kumar A, Bhardwaj B, Pawan N. Glyceryl trinitrate patch in management of preterm labour. J Obstet Gynaecol India. 51(6):55-57 2001.

13. Simhan HN, Cartis SN. Prevention of Preterm labour. NEJM 2007; 357: 477-87.

\section{AUTHORS:}

1. Chandana C.

2. Kasturi V. Donimath

\section{PARTICULARS OF CONTRIBUTORS:}

1. Assistant Professor, Department of Obstetrics and Gynaecology, VIMS \& RC, Bangalore.

2. Professor, Department of Obstetrics and Gynaecology, KIMS, Hubli.

\section{NAME ADDRESS EMAIL ID OF THE} CORRESPONDING AUTHOR:

Dr. Chandana $\mathrm{C}$, \#868, 9 $9^{\text {th }}$ Main, BTM Layout, $2^{\text {nd }}$ Stage, Bangalore -76 .

E-mail: chandanachandregowda@gmail.com

Date of Submission: 08/02/2014. Date of Peer Review: 10/02/2014.

Date of Acceptance: 24/02/2014.

Date of Publishing: 11/03/2014. 